\title{
Correction to: Linking the Linguistic Resources Using Graph Structure for Multilingual Sentiment Analysis
}

\author{
Mohamed Raouf Kanfoud (iD) and Abdelkrim Bouramoul $(\mathbb{D}$
}

\section{Correction to:}

Chapter "Linking the Linguistic Resources Using Graph Structurefor Multilingual Sentiment Analysis" in: X.-S. Yang et al. (eds.), Proceedings of Sixth International Congress on Information and Communication Technology, Lecture Notes in Networks and Systems 235, https://doi.org/10.1007/978-981-16-2377-6_88

The original version of the book was published with incorrect figure 4, updated figure given below. The chapter and book have been updated with the changes.

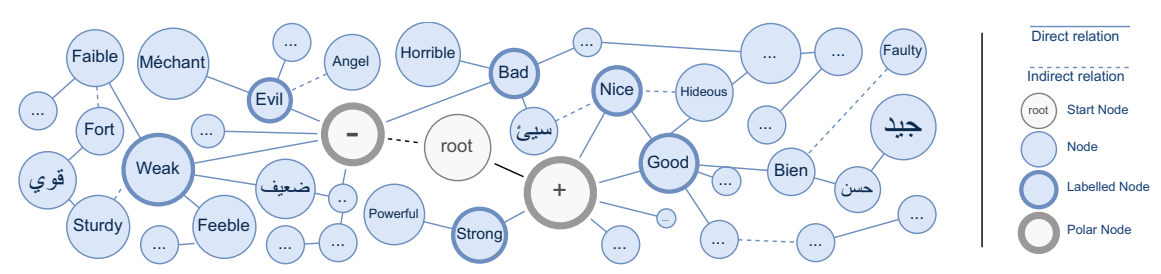

Fig. 4 A sample extracted from the graph used in the evaluation

The updated version of this chapter can be found at https://doi.org/10.1007/978-981-16-2377-6_88 